\title{
Sustainable Innovation: The Italian Scenario Studied Through Higher-Order Partial Least Squares-Path Modeling
}

\author{
Rosanna Cataldo ${ }^{1}$ (D) . Corrado Crocetta ${ }^{2}$. Maria Gabriella Grassia ${ }^{1}$. \\ Paolo Mazzocchi ${ }^{3}$. Antonella Rocca ${ }^{3}$. Claudio Quintano ${ }^{4}$
}

Accepted: 4 November 2021

(C) The Author(s), under exclusive licence to Springer Nature B.V. 2021

\begin{abstract}
What is the real meaning of sustainable innovation? How is sustainable innovation different from other forms of innovation? How does sustainable innovation contribute to societal development? How can we measure the sustainable innovation of a country-which indicators and which synthesis methods should we use? In this paper we try to answer these previous questions. Starting from the concept of sustainable innovation, as it has been extensively discussed in recent years in a range of disciplines from economics to engineering and sociology, the paper focuses on the basic criteria (such as indicators and statistical models) required to evaluate the sustainable innovation at the regional level, choosing Italy as a case study. From the elementary indicators of innovation, on one hand, and sustainability, on other hand, a composite indicator of sustainable innovation has been computed. The statistical model used to compute this composite indicator has been a Higher-Order Partial Least Squares Path model. The results obtained applying this model to the Italian scenario are discussed, the ranking of the different Italian regions, and the impact of the composite indicator sustainable innovation on economic results of each region are discussed.
\end{abstract}

Keywords Sustainable innovation · Sustainability · Innovation · PLS-path modeling • Higher-order construct

Rosanna Cataldo

rosanna.cataldo2@unina.it

1 Department of Social Sciences, University of Naples Federico II, vico Monte della Pietà, 1, 80138 Napoli, Italy

2 Department of Economics, University of Foggia, Largo Papa Giovanni Paolo II, 71121 Foggia, Italy

3 Department of Management and Quantitative Studies, University of Naples Parthenope, via Generale Parisi, 13, 80132 Naples, Italy

4 Department of Legal Sciences, University of Naples Suor Orsola Benincasa, Corso Vittorio Emanuele, 292, 80132 Naples, Italy 


\section{Introduction}

Various expressions and definitions for sustainability and innovation have been reported in the literature. Sometimes the two concepts are combined and described with one term, sustainable innovation. In the opinion of Maier et al. (2020), "the links between these two concepts are also related in the literature as sustainability-oriented innovation, or sustainability-related innovation".

Different researchers have used different terminologies to explain the concept of "innovation". One frequently used description is the definition adopted by the Organization for Economic Cooperation and Development (OECD). The most recent edition of the Oslo Manual (OECD-Eurostat, 2018b) considers innovation to be "a new or improved product or process (or combination thereof) that differs significantly from the unit's previous products or processes and that has been made available to potential users (product) or brought into use by the unit (process)".

In 1987, the Brundtland Commission defined sustainable development as: "Development that meets the needs of current generations without compromising the ability of future generations to meet their needs and aspirations" (WCED, Special Working Session, 1987). Since then, according to Maier et al. (2020), there has been considerable debate about the concept of sustainability with respect to issues of environmental protection. Indeed, we have found in the literature a great number of definitions for sustainability (Sodano, 2019). Initially, the global ecological crisis prompted a significant increase in interest in the concept of sustainability. Subsequently, understanding of this term has been extended to include all aspects of the quality of life, ranging from an economic to a social perspective. In fact, sustainable development implies an idea of progress integrating indivisible short- and long-term targets, economic and environmental arguments and positive action at both a local and global level. It involves the definition of a theoretical structure that can provide a stable foundation for the management of any situation encompassing both humans and the environment. All modifications to the current condition should prompt an analysis of the means necessary to effect the transformation to the new reality (Oksanen \& Hautamäki, 2015).

Combining the concept of sustainability with the concept of innovation seems an appropriate way to approach a new paradigm in which innovation has its roots in sustainable development and is based on ethically, socially, economically and environmentally sustainable principles. Similar principles can be seen in eco-innovation (Boons \& Lüdeke-Freund, 2013; Hall \& Clark, 2003; Rennings, 2000), in frugal innovation and engineering (Bhatti \& Ventresca, 2012), in Jugaad innovation (Radjou et al., 2012), and in the rise of the sharedvalue mindset (Porter \& Kramer, 2011). However, the concept of sustainable innovation is more elaborate (Oksanen \& Hautamäki, 2015).

As Ratten et al. (2019) have said, the word 'sustainable' when added to the word 'innovation' results in a broader approach to change. This observation results from a consideration of sustainability as a systemic approach to competitive market dynamics. In the past, innovation was viewed as falling within the realm of business and there was little discussion of the role of stakeholders in its development (Ratten, 2018). Since those times, this has changed with citizens becoming more vocal about their rights and those of corporations, which has resulted in sustainable innovation becoming a useful way to discuss innovations that place emphasis on all stakeholders such as customers, employees and regulatory agencies (Ratten \& Dana, 2017). This means that when practising innovation, the impact on local communities needs to be considered as well as the impact on advocacy 
groups. Sustainable innovation focuses on the social changes made possible as a result of innovation; this differs from the more specifically environmental focus of green innovation (Schiederig et al., 2012).

Research on sustainable innovation has grown in popularity due to the need to incorporate sustainability within business practices. Boons \& Ludeke-Freund (2013) have suggested that sustainable innovation can be analysed at three levels: organizational, interorganizational and societal. The organizational level involves focusing on firms and how they embed sustainable forms of innovation. In this analysis, it is useful to look at the role of leaders in managing change and their attitude towards sustainability. The inter-organizational level focuses on how firms collaborate and compete in relation to sustainable innovation. An increasing number of firms have partnerships, alliances and networks that enable them to share resources. This development helps in the building of a sense of community around sustainability initiatives. The societal level involves focusing on socio-demographic shifts in the environment. This concentration is important since there is a greater emphasis on the work/life balance and the way in which entities interact in the natural environment. Issues such as climate change are at the forefront of people's minds and this is reflected in their purchasing decisions.

As a matter of fact, in recent years, the literature has demonstrated a growing interest in public policies connected to the possibility of improving firms' efficiency in terms of sustainable innovation. The recent global economic crisis caused by the Covid-19 pandemic represents an unprecedented opportunity, and also a challenge, in terms of sustainable innovation. Indeed, to overcome the crisis, the European Commission has reshaped its priorities, addressing the European Green Deal as an essential tool to boost and recover the European economy, highlighting the importance of stimulating innovation and sustainability and providing the financial resources for the realisation of socio-economic recovery plans (the so-called Next Generation Plan for a more ecological, digital and resilient Europe).

For this reason, it is important to define useful indicators and useful statistical models in order to measure the emerging concept of the sustainable innovation of a country and to monitor its progress.

The measurement of sustainability problems via appropriate indicators has been widely used by scientific communities, governments, and policymakers. Indicators serve as a powerful tool in the evaluation of the impact of environmental issues. However, their selection is often subjective, and the choice of an indicator depends on factors such as whether or not it is cost-effective, easy to understand, scientifically reliable and internationally comparable (Agol et al., 2014). Nowadays, a set of 330 indicators, introduced in March 2015 for the implementation of the Sustainable Development Agenda 2030, are used. The 2015 United Nations General Assembly established this 2030 Agenda, consisting of an extensive set of global indicators, comprising 17 Goals (SDGs) and 169 Targets, a product of the combined activity of all stakeholders, representatives from government agencies, academics and general society (United Nations, 2015a; 2015b). In Italy, the Alleanza italiana per lo sviluppo sostenibile (ASviS) established an interactive on-line database that allows stakeholders, the media and the public to verify the progress of the nation with respect to the SDGs, using a wide range of statistical indicators (ASviS, 2021). The platform contains the time series of all the indicators, including those selected by the United Nations (UN) for the 2030 Agenda, released by the Italian national institute for statistics (Istat), as well as the composite indicators (CIs) relative to each SDG calculated by ASviS for Italy and the Italian regions. At the national level, ASviS monitors the country's progress with respect to the SDGs in its annual report. At 
the local level, in 2020 ASviS launched its first territorial report, which offers a detailed analysis of Italian regions, provinces and metropolitan cities, contributing to the territorialisation of the 2030 Agenda in Italy.

Concerning statistical models to investigate sustainability and well-being, a broad discussion has been presented by-among others-Alaimo \&Maggino (2020), Bianchi and Biffignandi (2020), Cataldo et al. (2020), Tomaselli et al. (2020), Alaimo et al. (2020), Alaimo et al. (2021), D’Urso et al. (2020), D'urso \&Vitale (2021). who have debated on the use of CIs in relation to these topics. Nevertheless, there are several limitations which restrict the use of Cis and these are discussed in Nardo et al. (2005), the OECD and Joint Research Centre-European Commission (2008), Peiró-Palomino and Picazo-Tadeo (2018), Alaimo and Maggino (2020) and Kuc-Czarnech et al. (2020).

Similarly to the literature on sustainability, different perspectives are also proposed when it comes to the definition of innovation, and different characterisations of innovation have led to the identification of different indicators for the monitoring of its changes. Among others, Becheikh et al. (2006), Freeman and Soete (2009), Evanschitzky et al. (2012), the OECD (2018b) and Van Holt et al. (2020) have debated extensively the issue that academic research does not denote a common overall innovation measurement framework. Nonetheless, a broad discussion persists about which indicators should be used to assess innovation. In less recent literature, Jaffe (1989) investigated the positive effect on innovation of university knowledge via patent statistics, while Griliches $(1984,1990)$ explored the use of patent data and Research \& Development (R\&D) expenditures. However, patent and R\&D data are subject to several criticisms. For instance, patents denote the output side of the innovation and not all patented inventions are realised in practice. Furthermore, some technological sectors patent more than others and R\&D spending efforts may not be connected to a specific innovation production but might also be performed strategically to raise costs to create barriers which will then discourage new potential rivals. To address these limitations, in addition to the traditionally used dimensions, different proxies and indicators have been proposed. Several research papers have distinguished direct (patents and R\&D; Becheikh et al., 2006) from indirect indicators (for instance, the percentage of ideas with commercialization potential; Dewangan \& Godse, 2014). Distinctions between process and product indicators should be considered as well (Dodgson \& Hinze, 2000). Significant advances in the use of innovative indicators have also been proposed by Rothwell (1992), Hagedoorn and Cloodt (2003), Smith (2005), Gössling and Rutten (2007) and Makkonen and van der Have (2013). For an extensive literature analysis of innovation advances, see Dziallas and Blind (2019). Nowadays, one of the most frequently used sets of indicators to assess the innovation level of European countries is the European Innovation Scoreboard (EIS; European Commission, 2020), while the Regional Innovation Scoreboard (RIS) (European Commission, 2021) represents a regional extension of the EIS. Compared to the EIS, the RIS assesses the innovation performance using a limited number of indicators. Furthermore, the fourth edition of the Oslo manual (OECD, 2018b) presented a detailed structure to classify innovation outcomes in terms of three different factors: the type of technology (process/product), the level of novelty (innovation in the firm or in the market) and commercial success. The OECD handbook also proposes a detailed updated guideline focusing on measuring innovation in the business sector.

In this paper, in accordance with the perspective proposed in the recent literature on both sustainability and innovation, we propose a set of indicators and a statistical model to measure sustainable innovation.

However, it is necessary to make some clarifications in order that the strategy adopted can be better understood: 
- the multidimensional nature of sustainable innovation has been considered and its dimensions have been identified;

- the sustainability indicators have been chosen from the ASviS database (https://asvis.it/ database-sugli-sdgs) from among those available at a regional level. Several indicators, although important, have not been included because they are not available at a regional level (such as some indicators of objective 12, relating to consumption and production, and objective 13 , relating to climate action);

- the innovation indicators have been chosen from the RIS and Amadeus database, referring to small and medium-sized enterprises (SMEs);

- starting from the Amadeus database, using a Boolean search strategy, we have created an indicator of the "propensity for innovation" of SMEs.

Furthermore, the authors hypothesise that the impact of sustainable innovation on economic outcome can be measured. Among others, Malesios et al. (2021) presented a comprehensive overview of recent research papers that have investigated sustainable practices considering the SMEs perspective; in their examination on the emerging relevance of sustainability for economic-environmental-social features of business, they widely debated on statistical methodologies that have been proposed in applied research to derive the relationships among the variables involved. In addition to Malesios et al. (2021), Shmueli et al., $(2016,2019)$ presented an extensive discussion on the causal explanation in theory building and testing. In line with these perspectives, in the current research, the authors' efforts have been directed to a specific model which is able to investigate the causal relationship between sustainable innovation and economic outcome. To compute the CI sustainable innovation a Higher-Order Construct (HOC) (Cataldo et al., 2017; Crocetta et al., 2021; Wetzels et al., 2009) has been used. This model, also known as a hierarchical (component) model (HCM), which is based on Partial Least Squares Path Modeling (PLS-PM) (Chin, 1998; Hair et al, 2011; Tenenhaus et al, 2005) refers to different latent constructs that represent the different dimensions of a phenomenon to be measured. Among the various models available, Dziallas and Blind (2019) analysed that Structural Equation Modeling (SEM) is one of the most used techniques to study innovation (almost $6.5 \%$ of the models that these authors investigated in their model overview adopt this approach).

The idea is to highlight that it becomes important, from a policymaker's and manager's point of view, to focus on different dimensions in order to improve a firm's sustainable innovation.

The paper is structured as follows. Section 2 reports the indicators for each dimension. The conceptual framework for sustainable innovation is presented in Sect. 3, and the data analysis and results in Sect. 4, including the results at a regional level in subsection 4.1. The framework is discussed in Sect. 5. The paper concludes with the key findings, policy implications and future research (Sect. 6).

\section{Sustainable Innovation: Geographical Level, Conceptual Dimensions, and Indicators}

In general, the European Commission (2021) highlighted that densely populated areas are more likely to be more innovative for several reasons, for instance because, with people and enterprises being at a closer distance, knowledge diffuses more easily. More possibilities favouring innovation derive from the concentration of government and educational 
services in urbanised areas which provide better training opportunities and encourage above-average proportions of highly-educated people.

Bottazzi and Peri (2003) noted that knowledge spillover effects are generally spatially bounded, while Avilés-Sacoto et al. (2020) highlighted that innovation research very often focuses on the comparative performance of different areas and analyses how each area is utilizing its own dedicated resources. Considering a non-different perspective, since Italian regions are different in terms of logistic structure, firm characteristics and environmental issues, etc., in the present paper we have fixed the regional levels (NUTS2 territorial districts) in order to explore sustainable innovation. The importance of the regional level in studying innovation has also been acknowledged by Asheim et al. (2011), Carayannis et al. (2018) and Hauser et al. (2018). Moura et al. (2017) have investigated the importance of the firm's location, and the OECD (2011) has highlighted that an effective innovation policy is typically targeted at delimited regions. This latter research paper has also emphasised that the spatial distribution of large firms may distort the measurement of territorial innovativeness. In the recent literature, in conjunction with the usage of spatial patterns, the involvement of certain economic sectors (specifically the NACE codes) has also increased. For instance, Eurostat $(2016 ; 2017)$ and Quintano et al. (2020) have followed an approach associated with NUTS2 territorial districts in combination with several NACE codes to perform specific policy interventions.

The dimensions of sustainable innovation have been chosen, starting from the considerations mentioned above, on the basis that sustainable innovation focuses on the social changes made possible by innovation (Ratten et al., 2019). Four dimensions have therefore been considered (Innovation of SMEs; Innovation of Company Standards; Lifelong Learning Opportunities and Innovative Potentials), of which the first two relate to corporate innovation and the second two to social sustainability. Finally, a fifth dimension (Economic Impacts) has been considered to understand if sustainable innovation could have any influence on this. Among the many determinants of sustainable innovation, the above dimensions have been identified as relatively more significant than others.

Table 1 shows the indicators chosen and the respective sources, for each dimension. These dimensions will be discussed extensively in the next sections.

\subsection{First Dimension: SME's Innovation}

The dimension SME's Innovation concerns five indicators, Potentially Innovative SMEs (POT_INN_SMES), Innovative SMEs according to the Law Decree 3/2015 (INN_ SMES), Innovative Start-ups (INN_START), Spin-offs (SPIN_OFF), and PhD Employees (PHD_E).

Emphasis was given to SMEs, in agreement with many authors including Durst and Edvardsson (2012), on the grounds that SMEs are considered the engines of the most important economies in the world. The importance of SMEs is very high in Italy, where they produce $66.9 \%$ of the total value of the national "non-financial business economy", a percentage significantly higher than the EU average of 56.4\%. In Italy SMEs also account for about $78.1 \%$ of total employment, compared to the EU average of $66.6 \%$, with microfirms playing a particularly important role, generating $44.9 \%$ of employment opportunities compared to the EU average of $29.7 \%$ (European Commission, 2019).

The notion of 'innovative SMEs' refers to the definition stated by the Law Decree (LD) $3 / 2015$, further updated by the LD 135/2018. This definition includes SMEs characterized by a high innovation component, employing fewer than 250 employees, with an annual turnover 


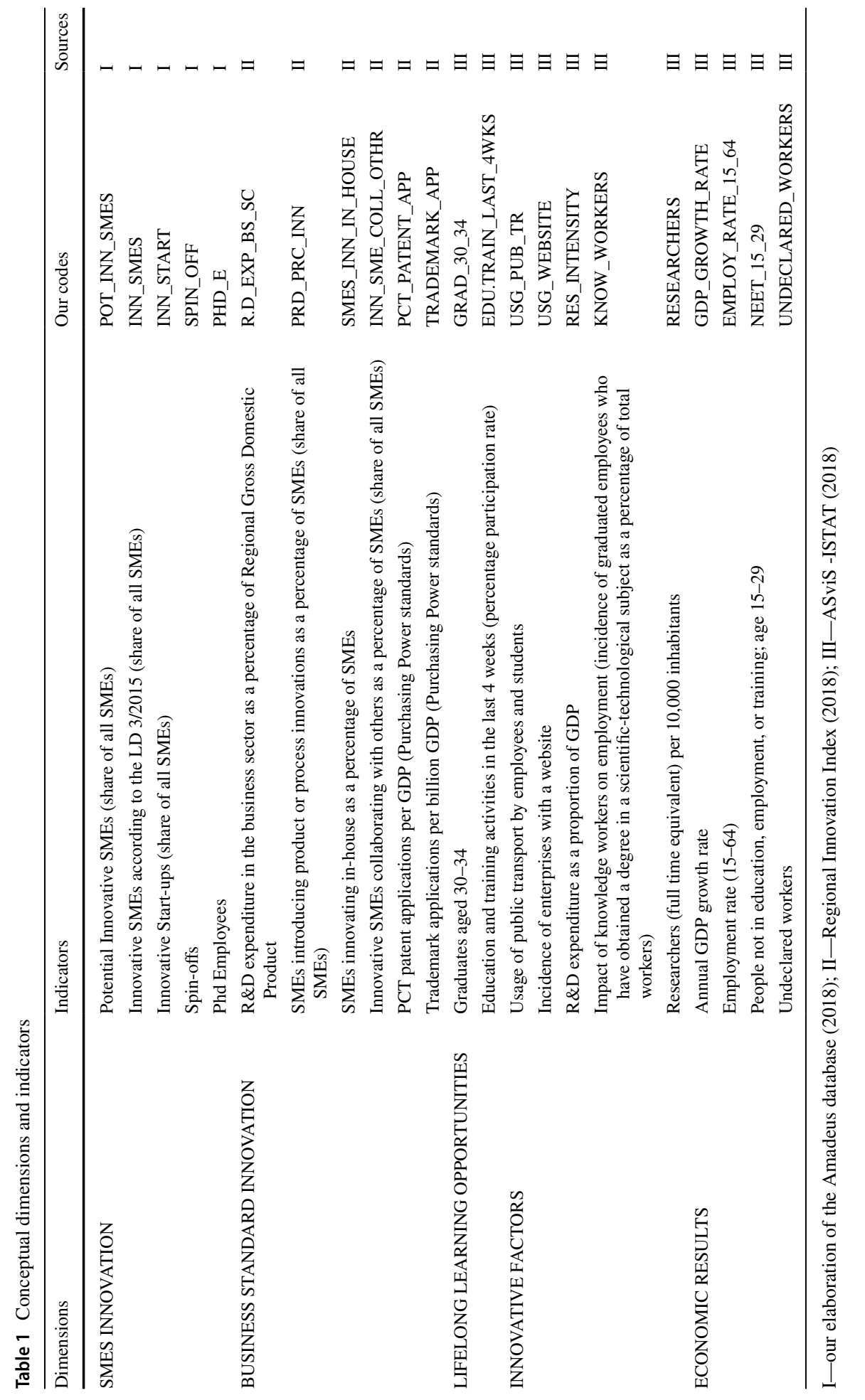


which does not exceed 50 million euros. Additional requirements for innovative SMEs are as follows: a limited company; a headquarters in Italy; a R\&D expenditure equal to at least $3 \%$ of turnover (or annual costs); and at least $1 / 5$ of employees having a $\mathrm{PhD}$ (or at least $1 / 3$ holding a Master's degree). Firms that meet all the requirements can be registered in the innovative SMEs special section of the business register of the Italian Chamber of Commerce. LD $3 / 2015$ also establishes several requirements to change the status from SMEs to innovative SMEs. The justification for changing status is that innovative SMEs have several facilities, also including fundraising through equity crowdfunding campaigns (Lukkarinen et al., 2016). In fact, innovative SMEs can benefit from most of the support measures targeted only at innovative start-ups in accordance with LD 179/2012 (the Italian Start-up Act). ${ }^{1}$

There are other SMEs that could become innovative but are not able to do so because they do not meet all the requirements. In particular, the ratio between the financial items connected to R\&D and turnover represent an essential and significant prerequisite to consider a SME "potentially innovative".

In accordance with the previous definitions, the number of innovative (INN_SMES) and potentially innovative (POT_INN_SMES) SMEs for each Italian region has been calculated from the Amadeus database (Bureau van Dijk, 2010). Furthermore, as indicated by the OECD (2018a), only the NACE categories strictly dependent on innovation have been considered.

The INN_SMES indicator, therefore, represents the number of SMEs (share of all SMEs), operating in the NACE sectors indicated in Table 2, registered with the Italian Chamber of Commerce as "innovative SMEs".

The POT_INN_SMES indicator, on the other hand, represents the number of SMEs with fewer than 250 employees, also operating in the NACE sectors indicated in Table 2, not registered as "innovative SMEs", but with specific financial needs in terms of R\&D, ${ }^{2}$ or as "potentially" innovative SMEs.

A total of 103,347 Italian companies has been involved in the empirical analysis. ${ }^{3}$

Acs et al. (2009) highlighted that starting an innovative venture requires both knowledge and entrepreneurial talent, and Fritsch and Aamoucke (2013) noted a strong relationship between Public Research Institutes and innovative businesses. According to these perspectives, several additional variables might be conceptually relevant to innovation, such as Innovative Start-ups (INN_START), Spin-offs (SPIN_OFF) and PhD Employees (PHD_E). Although these indicators could have a significant contribution to the analysis, they have been removed from the statistical model presented in paragraph 3.1 since these measurements (and their proxies) presented several criticisms. These weaknesses derive from the lack of the consistency of available data, which negatively impacted the model's goodness of fit.

\subsection{Second Dimension: Business Standard Innovation}

Business capabilities include the knowledge, competencies and resources that a firm accumulates over time. Dahlander and Gann (2010) highlighted that firms draw on external sources of knowledge for their innovation activities. The knowledge involves multiple actors such as higher education institutions, public research institutions, customers as users

\footnotetext{
1 See OECD (2018a) and MISE (2020) for an extensive description of these features.

2 In detail, the first and third quartiles, referring to the financial ratios used to assess the incidence of R\&D on the turnover of innovative SMEs, have been fixed.

3 The extensive perspective proposed in this paper includes several weaknesses, which can derive, for instance, from the NACE classification of the firms involved, which may change over several years, as compared to the activity declared by the establishment upon its foundation.
} 
Table 2 Economic activities connected with business innovation (NACE)

\begin{tabular}{lll}
\hline Section & Division & Description \\
\hline B & $05-09$ & Mining and quarrying \\
C & $10-33$ & Manufacturing \\
D & 35 & Electricity, gas, steam and air conditioning supply \\
E & $36-39$ & Water supply, sewerage, waste management and remediation activities \\
F & $41-43$ & Construction \\
G & $45-47$ & Wholesale and retail trade, repair of motor vehicles and motorcycles \\
H & $49-53$ & Transportation and storage \\
J & $58-63$ & Information and communication \\
K & $64-66$ & Financial and insurance activities \\
L & 68 & Real estate activities \\
M & $69-75$ & Professional, scientific, and technical activities \\
\hline
\end{tabular}

Source: Eurostat (2018); OECD (2018)

of product innovations, and private individuals. Arbolino et al. (2018) emphasised that any improvement in innovation level requires a co-operation between public and private sectors for research and technological development. Consequently, the dimension Business Standard Innovation considers some of these features. The following indicators have been selected from the RIS database (European Commission, 2021): $R \& D$ expenditure in the business sector as a percentage of Regional Gross Domestic Product (R.D_EXP_BS_SC) has been selected because it denotes new knowledge within firms, especially in pharmaceuticals, chemicals or different science-based sectors which involve R\&D laboratories; SMEs introducing product or process innovations as a percentage of SMEs (PRD_PRC_INN) has been selected because the technological innovation can be measured in terms of the introduction of new products (goods or services) and processes; SMEs innovating in-house as a percentage of SMEs (SMES_INN_IN_HOUSE) refers to the number of SMEs with inhouse innovation activities; Innovative SMEs collaborating with others as a percentage of SMEs (INN_SME_COLL_OTHR) assesses the level of co-operation in innovation among SMEs since establishing an advanced innovation initiative is often predicated on the ability of a company to access diverse sources of data and to collaborate with other agencies on project development. It is an indicator that evaluates the flow of knowledge among firms and between public research institutions and firms; PCT patent applications per GDP (PCT_PATENT_APP) indicates the number of patent applications at the European Patent Office, since that the number of patents can be considered as a measure of the capacity of a firm to develop new products and determines their competitive advantage; and Trademark applications per billion GDP (TRADEMARK_APP) identifies the origin of goods and services and guarantees consistent quality.

\subsection{Third Dimension: Innovative Factors}

The third dimension Innovative Factors reflects the ASviS indicators of Goal 9 (Build a resilient infrastructure, promote inclusive and sustainable industrialization and foster innovation). Usage of public transport by employees and students (USG_PUB_TR) refers to the sustainable infrastructure to support economic development and human 
well-being. Researchers (full-time equivalent) per 10,000 inhabitants (RESEARCHERS), Research and development expenditure as a proportion of GDP (RES_INTENSITY), and Impact of knowledge workers on employment (KNOW_WORKERS) denote the R\&D expenditure, scientific research and technological capabilities of regional industrial sectors. The incidence of enterprises with a website (USG_WEBSITE) indicates the level of access of the enterprise to information and communications technology.

\subsection{Fourth Dimension: Lifelong Learning Opportunities}

This construct considers the social dimensions connected with Education and training activities in the last 4 weeks (EDU_TRAIN_LAST_4WKS), which refers to SDG-Goal 4 and measures the participation rate of young people and adults in formal and non-formal education and training, and Graduates aged 30-34 (GRAD_30_34) which indicates the share of the population 30-34 years old who have completed tertiary education. Istat (2019) emphasised the relevant role played by this Goal in developing educational systems capable of providing adequate numeracy and literacy skills, thereby trying to minimize inequalities in skills and knowledge.

\subsection{Fifth Dimension: Economic Results}

This dimension is connected to several economic findings. In more detail, it includes, firstly, an indicator measuring GDP per capita and annual GDP growth rate (GDP_ GROWTH_RATE), which prevalent literature suggests as appropriate for interpreting real income differences between regions. In addition, it includes indicators connected to (1) people not in education, employment, or training between 15 and 29 years old (NEET_15_29) (Caroleo et al., 2020); (2) the issue of undeclared work which affects businesses and workers in Italy (UNDECLARED_WORKERS) and (3) the employment rate (EMPLY-RATE_15_64) (Quintano \& Mazzocchi, 2020).

\section{Conceptual Framework for Sustainable Innovation: The Higher-Order PLS-PM Model}

The construction of CIs implies the search for a suitable synthesis of directly measurable elementary indicators in order to achieve a simple representation of a multidimensional phenomenon (Crocetta et al., 2021). CIs constitute an effective way of summarising the data deriving from the base indicators, so providing the means for a general evaluation of different countries, taking into consideration a wide range of factors and allowing a ranking from best to worst. (Crocetta et al., 2021). 
The research challenge is to identify suitable instruments to determine CIs able to synthesize and represent multidimensional phenomena. There are many and varied approaches in the literature, based on either simple or complex aggregation techniques. For a detailed explanation about CIs, see Nardo \& Saisana (2005), Trinchera et al., 2008 and Lauro et al. (2018). Among all the possible statistical methods, it is recommended that the PLS-PM be used. For a detailed explanation about the advantages of using PLSPM for the construction of a CI see Cataldo et al. (2017), Lauro et al. (2018), Crocetta et al. (2021).

Generally, latent variables reflect the nature of the phenomenon consistently with the conceptual model (Alaimo, 2020) and their identification is founded on empirical statements so that the defined variable can reflect the nature of the considered phenomenon consistently with the conceptual model (Maggino, 2017). Almost all measurement processes of socio-economic phenomena adopt a formative model. This means that an index that must be formulated is not an entity in itself but exists as a composite measure composed of a group of individual indicators or pillars which are not interchangeable. For a detailed explanation see Alaimo (2020) and Maggino (2017).

As seen above, Sustainable Innovation is a multidimensional phenomenon, measured by a set of non-interchangeable individual indicators. For this reason, according to Lauro et al. (2018) and Mazziotta and Pareto (2018), we have proposed a CI obtained using a SEM (Kaplan, 2008) PLS-PM model (Tenenhaus et al., 2005) for hierarchical constructs (HOCs) (Chin, 1998; Hair Jr et al., 2016, Cataldo et al., 2017; Lauro et al., 2018; Hair et al., 2019).

The SEM path model is made up of two elements, the measurement model (also called the outer model), which describes the relationships between the Manifest Variables (MVs) and their respective Latent Variables (LVs), and the structural model (also called the inner model), which describes the relationships between the LVs. The SEM PLS-PM approach involves the use of an iterative algorithm, that makes it possible to compute, first, an estimation of the concepts, (LVs), which can only be measured by means of a set of indicators (MVs), and, secondly, the relationships between them, which can be measured by means of an interdependent system of equations predicated on multiple and simple regression (Lauro et al., 2018). In the content of PLS-PM models, HOCs have shown an increasing popularity in the last few years for the investigation of this kind of model with a high level of abstraction, in cases where the building of a system of indicators depends on different levels of construction.

HOCs in PLS-PM are considered as explicit representations of multidimensional constructs which exist and relate to other constructs at a higher level of abstraction, thereby mediating completely the influence received from or exerted on their underlying dimensions (Chin, 1998). Different approaches have been developed and proposed in the literature. For a detailed discussion and step-by-step illustration of these approaches, see Hair et al. (2016) and Cataldo et al. (2017).

Sustainable Innovation could be conceived of as a third-order construct, which is influenced by the second-order dimensions, which in turn are determined by the first-order dimensions: SMEs Innovation and Business Standard Innovation for Firms Innovation, and Lifelong Learning Opportunities and Innovative Factors for Social Sustainability. Economic Results assumes the role of an outcome.

Thus, a path diagram has been constructed (Fig. 1) with four LVs of the first-order, two LVs (Firms Innovation and Social Sustainability) of the second-order and one LV of the third-order (Sustainable Innovation), which impacts on a LV, synthesis of economic findings. The LVs (dimensions) and the MVs (indicators) related to each first-order LV have been described in detail in Table 1 Sect. 2. 
To investigate the statistical significance of the relationship, the general form of Sustainable Innovation is expressed by the following equation:

$$
\text { Sustainable Innovation }=f(\text { Firms Innovation; Social Sustainability) }
$$

The model is a reflective-formative-formative structural model, resulting from the combination of reflective Lower Order Constructs (LOCs) and a formative HOC. A Mixed Two-Step Approach has been applied in order to estimate the HOC dimensions (Cataldo et al., 2017).

\section{Data Analysis and Results}

The analysis has been developed with reference to the Italian regions and therefore the number of units considered is 20. The paper focuses on 2018 (the last year available). However, for some variables, due to the lack of data for that year, data from the previous year has been taken as the reference.

The indicators selected have different units of measurement and scales, and thus require normalization to transform them into a common scale for developing a common indicator.

The normalization process is used throughout scientific research and is motivated by a variety of circumstances, and Pollesch and Dale (2016) noted that's plethora of normalization functions are utilized in sustainability assessment. Mazziotta and Pareto (2018) highlighted that normalization is required before any data aggregation transforming indicators into dimensionless values and that comparability of the composite indexes strictly depends on the normalization method. In general, there are various normalization methods (Joint Research Centre-European Commission, 2008), and some of the most common are as follows:

- The Min-Max normalization represents a rescaling procedure that performs a linear transformation that preserves the relationships among the original data values. This technique normalises indicators by subtracting the minimum value and dividing by the range of the indicator values. Although extreme values (or outliers) could distort the transformed indicators, Joint Research Centre-European Commission (2008) stated that the most frequently used technique in building composite indicators are Min-Max transformation and Z-scores.

- In the Z-scores normalization (standardization) the values are normalized based on the average and standard deviation. This method of normalization is useful when there are outliers that dominate the min-max normalization. A variation of this Z-scores replaces the standard deviation by the mean absolute deviation, which is more robust to outliers than the standard deviation (Han et al., 2011). Mazziotta and Pareto (2017) listed additional pros and cons of normalisation methods.

- The Mazziotta-Pareto Index (MPI) is based on a non-linear function starting from the arithmetic mean, which introduces a penalty for the units with unbalanced values of the indicators. This method provides a robust measure not very sensitive to the inclusion (or exclusion) of specific indicators (Mazziotta et al., 2010). The Adjusted MPI (AMPI) represents a variant of the MPI for spatio-temporal comparisons. Mazziotta and Pareto (2017) underlined that AMPI allows computing the score of each unit independently of the other, while MPI requests the mean and standard deviation of the individual indicators. 




Fig. 1 HOC path diagram

- The Jevons index is defined as an unweighted geometric mean of ratios, and its application can lead to either 'static' or 'dynamic' measurements (Massoli et al., 2013). Since the compensability among indicators is defined as the possibility of compensating any deficit in one dimension with a suitable surplus in another, and since an aggregation approach can be defined as compensatory or non-compensatory (or partially compensatory) depending on whether it permits compensability or not, this index still maintains the non-compensatory connotation such as MPI and AMPI. See Mazziotta and Pareto (2018) and Sessa (2016) for an extensive discussion on these topics.

In addition to the above-mentioned approaches, several different approaches for normalisation and aggregation techniques are broadly discussed in Mazziotta and Pareto (2017), Nardo et al. (2005) and Joint Research Centre-European Commission (2008). This current paper refers to the Min-Max normalization technique since it is broadly used across several development indices, as widely discussed - among others - by Khalid et al. (2020) and Mazziotta and Pareto (2018).

Equation (2) is the simple expression used for the normalization of each variable. Given a variable $\mathrm{X}=\left\{\mathrm{x}_{1}, \ldots \mathrm{x}_{\mathrm{i}}, \ldots, \mathrm{x}_{\mathrm{n}}\right\}$, the Min-Max for a generic unit $\mathrm{x}_{\mathrm{i}}$ is computed as follows:

$$
Z=\frac{X-\min (X)}{\max (X)-\min (X)}
$$

Since all the indicators must have the same direction compared to the other indicators of the measurement model (Ringle \& Sarstedt, 2016), two variables (NEET_15_24 and UNDERCLARED_WORKERS) required a transformation of their original scale. Therefore, these indicators have been inverted, changing their sign, according to the rescale procedure suggested by Mehmetoglu and Venturini (2021) and Casadio Tarabusi and Guarini (2013; also known as 'Imputation of correct signs').

Three variables, initially involved in the model, were removed from the analysis as they presented no significant loadings: INNO_START, SPIN_OFF and PHD_E.

An XLSTAT statistical and data analysis solution (Addinsoft, 2020) has been used to perform the PLS-PM analysis involving formative indicators and the centroid scheme for the inner estimation. This structural model assessment, estimated by means of the 
PLS-PM approach, encompasses measures of quality of both the inner and outer model. Concerning the outer model assessment, since all the MVs of the LOC have been treated in a reflective way (each MV reflects-and it is an effect of - the corresponding LV), it is important to verify that the blocks of MVs linked to each LV represent the same concept.

Table 3 presents a checking of the homogeneity and the one-dimensionality of the constructs, showing three main indices-Cronbach's $\alpha$, Dillon-Goldstein's $\rho$ (or Jöreskog's $\rho$ ) and PCA eigenvalues. These measures confirm that the model assumptions seem to be appropriate (the values of the Cronbach's $\alpha$ and Dillon-Goldstein's $\rho$ are greater than 0.7 (Tenenhaus et al., 2005) and the first eigenvalues are greater than 1 for all the LVs). The outer model is well specified, and the LVs are well measured by the MVs, their synthesis being good.

Table 4 reports the main indices indicating the overall model quality: the $\mathrm{R}^{2}$ coefficient and the Communality and Redundancy indices. The $\mathrm{R}^{2}$ coefficient shows that the endogenous LVs are well predicted by the explanatory LVs, while the values of the Communality and Redundancy indices are appreciably higher for all blocks (a value of 0.50 indicates a sufficient degree of construct validity). In Table 4 the Goodness of Fit Index (GoF) is also reported, showing an absolute value of 0.833 and a relative value of 0.963 , values which reflect a high quality of the constructs.

The outer estimations are shown in Table 5. The loadings are all positive and statistically significant. The least correlated variables are: INN_SME_COLL_OTHR for the LV Business Standard Innovation; USG_PUB_TR for the LV Innovative Factors and GDP_ GROWTH_RATE for the LV Economic Results.

To assess the significance of the path coefficients, Table 6 reports the value and significance of the structural coefficients linking the LOC dimensions to the HOC dimensions.

The path coefficients are all positive and statistically significant, having positive bootstrap confidential intervals. All the dimensions of the first-order dimensions are important for their constructs, respectively. Social Sustainability has a significant role in Sustainable Innovation, with a path of 0.606 , followed by Firms Innovation, with a path of 0.453. Finally, Sustainable Innovation has a significant influence on Economic Results with a path coefficient equal to 0.865 . Looking at the path coefficients, it appears that SustainableInnovation depends on its latent variables expressing the equation in the following form:

Sustainable Innovation $=0.453 \times$ Firms Innovation $+0.606 \times$ Social Sustainability

This expression shows how much the Sustainable Innovation index increases/decreases for each unit of variation of each explanatory component.

\subsection{Results at Regional Level}

Table 7 shows the scores of the Italian regions for each LV. The mean for each group ${ }^{4}$ and the general mean are also reported. The regional scores for the exogeneous LVs are computed as a weighted sum of their optimally quantified items with the corresponding MV loadings. The regional scores for the LVs are computed as a weighted sum of the score of the different exogenous LVs with the corresponding path coefficients. Since the values for Sustainable Innovation level varying from 0 to 100, a value close to 0 stands for a low level of sustainable innovation while a value close to 100 stands for a high level.

$\overline{4}$ The Italian regions are clustered into five groups according to the NUTS1 classification. 
Table 3 Block unidimensionality

\begin{tabular}{llllll}
\hline LVs & Dimensions & Cronbach's $\alpha$ & $\begin{array}{l}\text { Dillon- } \\
\text { Gold- } \\
\text { stein's } \rho\end{array}$ & First eigenvalue & Second eigenvalue \\
\hline $\begin{array}{l}\text { SMEs innovation } \\
\quad 2\end{array}$ & 0.766 & 0.895 & 1.621 & 0.379 \\
$\quad \begin{array}{l}\text { Business standard innova- } \\
\quad \text { tion }\end{array}$ & 6 & 0.902 & 0.928 & 4.135 & 0.937 \\
$\quad$ Firms Innovation & 2 & 0.662 & 0.855 & 1.494 & 0.506 \\
$\quad$ Lifelong learning oppor- & 2 & 0.938 & 0.970 & 1.883 & 0.117 \\
$\quad$ tunities & & 0.824 & 0.880 & 2.999 & 1.111 \\
$\quad \begin{array}{l}\text { Innovative factors } \\
\quad \text { Social sustainability }\end{array}$ & 2 & 0.880 & 0.943 & 1.786 & 0.214 \\
$\quad$ Sustainable innovation & 2 & 0.890 & 0.948 & 1.801 & 0.199 \\
Economic results & 4 & 0.846 & 0.911 & 2.977 & 0.941 \\
\hline
\end{tabular}

Table 4 Overall model quality

\begin{tabular}{|c|c|c|c|c|c|c|}
\hline LVs & Type & $\mathrm{R}$ square & Communality & Redundancy & Absolute GOF & Relative GOF \\
\hline SMEs innovation & Exogenous & & 0.800 & & 0.833 & 0.963 \\
\hline $\begin{array}{l}\text { Business standard } \\
\text { innovation }\end{array}$ & Exogenous & & 0.688 & & & \\
\hline Firms innovation & Endogenous & 0.995 & 0.747 & 0.746 & & \\
\hline $\begin{array}{l}\text { Lifelong learning } \\
\text { opportunities }\end{array}$ & Exogenous & & 0.941 & & & \\
\hline Innovative factors & Exogenous & & 0.594 & & & \\
\hline Social sustainability & Endogenous & 0.997 & 0.893 & 0.893 & & \\
\hline $\begin{array}{l}\text { Sustainable innova- } \\
\text { tion }\end{array}$ & Endogenous & 0.985 & 0.901 & 0.887 & & \\
\hline
\end{tabular}

Figure 2 visually shows the main PLS-SEM results. In more detail, Fig. 2 (a) highlights great differences between the different regions of Italy, according to an approach associated with NUTS1 territorial districts (North-East, North-West, Centre, South and Islands). Figure 2 (b) indicates the relationship stated in the procedure between Sustainable Innovation and Economic Results. The top right quadrant of this scatter plot indicates that regions belonging to the North (East and West) and to the Centre of Italy present the best scores concerning this pair of variables taken into consideration.

\section{Discussion}

As seen above, the results are different across the Italian regions: the regions in the north-east, north-west and centre present average values higher than the general Italy mean for all LVs. In particular, the regions of north Italy have the highest values of the LV Sustainable Innovation and consequently of the LV Economic Results. However, the heterogeneity of the Italian regions is well known. Since the start of this century, the economic inequalities within Italy have been growing steadily (OECD, 2018b). For 
instance, the GDP per capita in Bolzano-Bozen, an autonomous province in the north of Italy, was in 20162.5 times higher than that of Calabria in the south of the country. Between 2000 and 2016 Bolzano-Bozen experienced a $0.2 \%$ increase in productivity, the highest rate among all the regions of Italy, even if well below the OECD average of $1.1 \%$ for the same time period. This sustained economic improvement in BolzanoBozen is in sharp contrast with the economic decline observed in other regions. For example, the economy of Molise in the south of Italy experienced a contraction of about $-1 \%$ per year, a trend particularly pronounced since 2010 , so further increasing the economic disparity with the more prosperous regions of the north. Considering youth unemployment, although there has been a modest improvement in the last few years, the unemployment rate of young people in Calabria, over 55\%, remains one of the highest of all OECD areas. Youth unemployment rates also exceed 50\% in Puglia, Campania and Sicily, all regions in the south of Italy. In contrast, the youth unemployment rate of the province of Bolzano-Bozen, $10 \%$ in 2017, is the lowest in all of Italy. Additionally, with respect to general unemployment, the regional inequalities within Italy are greater than those of any other OECD country.

The COVID-19 pandemic has thrown these findings into sharp relief. However, the European agreement of July 2020 and the launch of the Next Generation EU program, in particular the Recovery and Resilience Facility, represents an extraordinary opportunity to relaunch the Italian economy and bridge these regional disparities, through objectives and resources that were lacking after the 2008 crisis.

Indeed the Recovery and Resilience Facility plan can become a potential response policy to ensure a fair transition for the most vulnerable areas, restoring hope to regions that in the last thirty years have been impoverished and have seen their networks of social, health, school and university infrastructures gradually weaken.

This consideration highlights the importance of improving innovation and sustainability, encouraging all possible research activities on sustainable innovation in the business (and SMEs) sector.

The results obtained in this paper support the basic ideas of the Recovery and Resilience Facility plan, with at least two positive conclusions:

- The model shows that the LV Sustainable Innovation has a high impact on the LV Economic Results. This LV has all loadings positive and statistically significant: even if the regional GDP is poorly correlated, as sustainable innovation increases, the employment rate increases and the rate of NEETs and undeclared workers decrease.

- Both Firms Innovation (with a path of 0.453), and Social Sustainability (with a path of 0.606) have a significant influence on Sustainable Innovation. This means that education, university training and scientific research are very important factors in relation to sustainable innovation and, consequently, for economic results.

In conclusion, an improvement in sustainable innovation could definitely be the right way to tackle the economic and social emergency linked to the employment of the next generation. 





Table 6 The inner estimation

\begin{tabular}{|c|c|c|c|}
\hline LVs & Path coefficient & Standard error & Confidence interval (95\%) \\
\hline SMEs innovation-> Firms innovation & 0.509 & 0.029 & {$[0.428 ; 0.541]$} \\
\hline $\begin{array}{l}\text { Business standard innovation }->\text { Firms } \\
\text { innovation }\end{array}$ & 0.643 & 0.055 & {$[0.522 ; 0.808]$} \\
\hline $\begin{array}{l}\text { Lifelong learning opportunities }->\text { Social } \\
\text { sustainability }\end{array}$ & 0.522 & 0.022 & {$[0.469 ; 0.564]$} \\
\hline Innovative factors $->$ Social sustainability & 0.537 & 0.022 & {$[0.476 ; 0.582]$} \\
\hline Firms innovation $->$ Sustainable innovation & 0.453 & 0.045 & {$[0.335 ; 0.538]$} \\
\hline $\begin{array}{l}\text { Social sustainability-> Sustainable innova- } \\
\text { tion }\end{array}$ & 0.606 & 0.035 & {$[0.530 ; 0.697]$} \\
\hline Sustainable innovation $->$ Economic results & 0.865 & 0.045 & {$[0.739 ; 0.936]$} \\
\hline
\end{tabular}

\section{Final Remarks}

The European agreement of July 2020 and the launch of the Next Generation EU program, in particular the Recovery and Resilience Facility, represent an extraordinary opportunity to relaunch the Italian economy, building back better, with innovation, sustainability and an increased attention on the problems of social unease and inequality.

Measuring and monitoring sustainable innovation is, more than ever, a fundamental issue and it will become increasingly important, in the next years, in order to understand the effects of investments in sustainable innovation on the economic results of a country.

In this paper we aim to propose a methodological framework and a prototype tool that may be useful to evaluate the sustainable innovation of the Italian regions. Starting from the concept of sustainable innovation, the paper has focused on the indicators and statistical models necessary for its evaluation. The most suitable indicators have been identified for the expression of the multidimensional concept of sustainable innovation, selected from the databases available for the study of, on the one hand, innovation and, on the other, sustainability. We have investigated sustainable innovation focusing on innovative or potentially innovative SMEs, which form one of the leading sectors of the Italian economy.

Among all the possible statistical methods, a Higher-Order PLS-PM has been used to compute the CI Sustainable Innovation and estimate its impact on Economic Results. The choice of using PLS-PM has been effective not only in reducing the dimension but also in finding any relations between CIs and their blocks (SMEs Innovation, Business Standard Innovation, Lifelong Learning Opportunities, Innovative Factors and Economic Results).

The results confirm the difference between the Italian regions and highlight also a strong impact of Sustainable Innovation on Economic Results (regional GDP, employment rate and inverse NEETs and undeclared workers indices).

Future research could involve the implementation and development of this model for all European countries. Even if the Italian regulatory framework is different from that of other European countries, the model could be extended to such territories, since the key characteristics proposed in the research, for example in terms of the innovative NACE codes considered, have been established according to the OECD (2018b) manual and therefore are suitable for international comparisons.

Another future research project could be a time series analysis, completed through the implementation of a longitudinal PLS-PM model. 


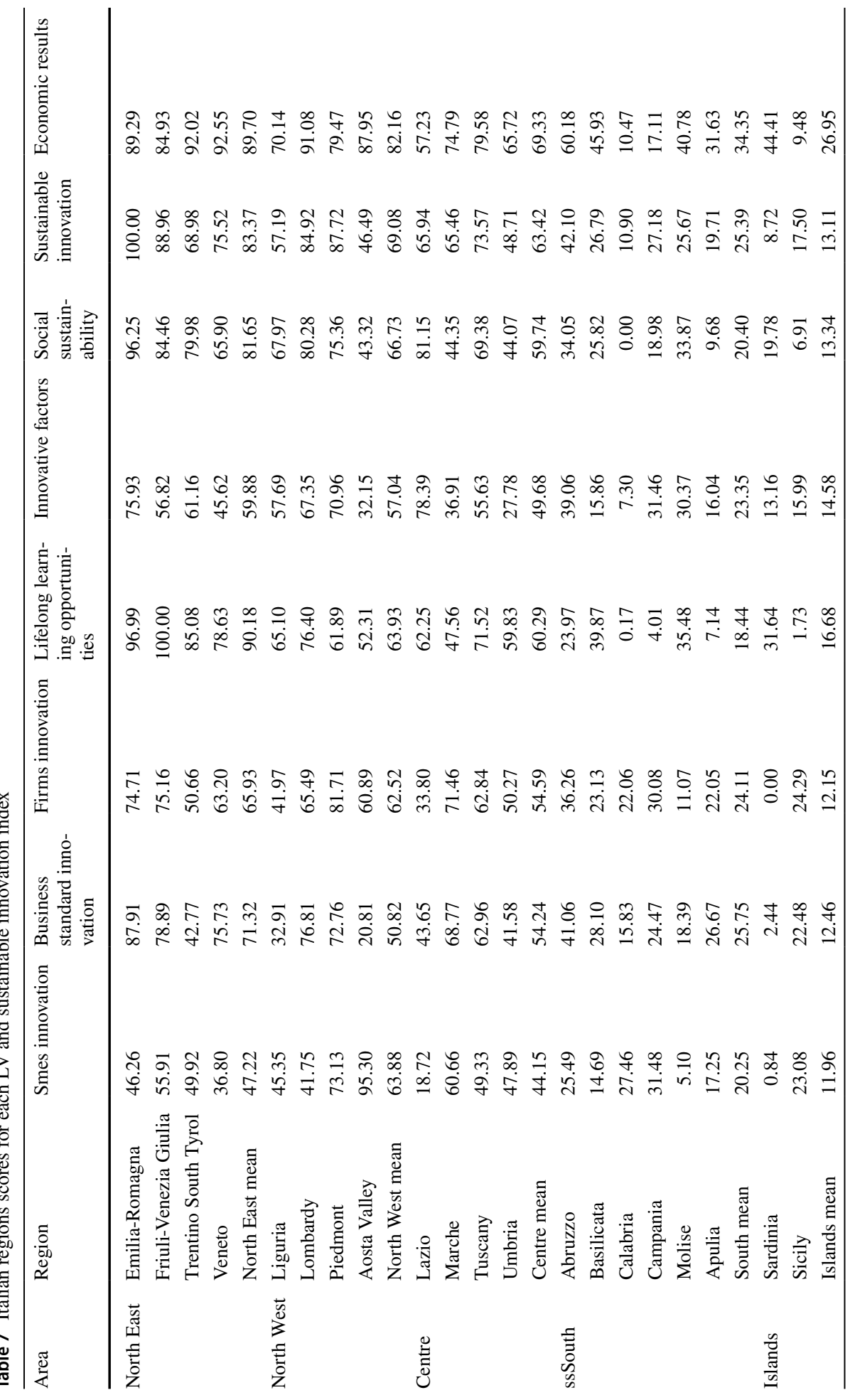




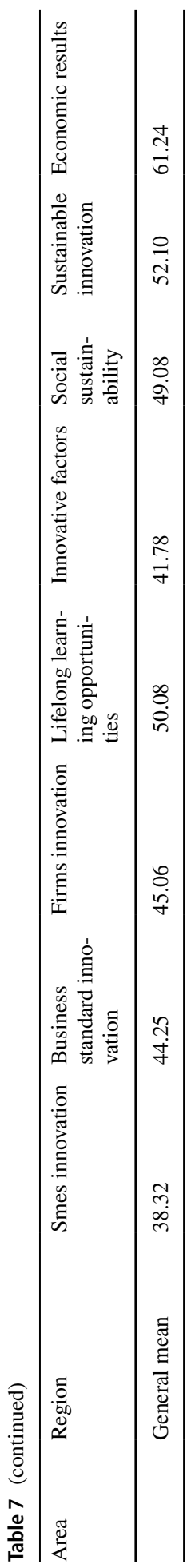

Springer 

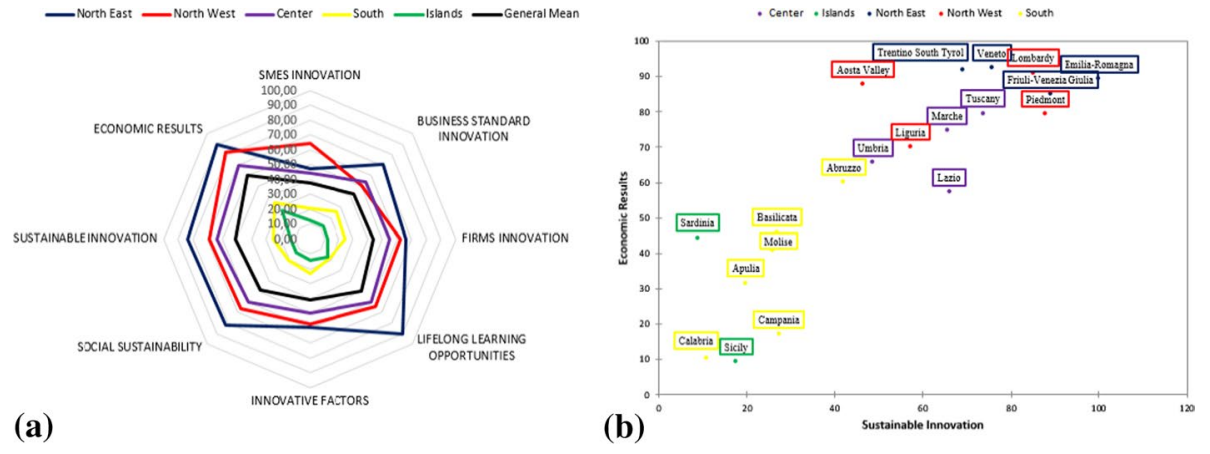

Fig. 2 Regional model results

Furthermore, we would like to include more indicators in the future, for example environmental indicators and dimensions. However, although data on economic indicators are widely available for most countries or regions, data on environmental and social indicators are unfortunately often incomplete and of poor quality.

The possibility of obtaining data, and above all data of quality, at the local level must be a political priority. Only in this way will it be possible to monitor the actions implemented using the funds of the recovery plan and to take full advantage of the extraordinary opportunity provided to relaunch the Italian economy and thereby bridge the regional disparities.

\section{References}

Acs, Z. J., Braunerhjelm, P., Audretsch, D. B., \& Carlsson, B. (2009). The knowledge spillover theory of entrepreneurship. Small Business Economics, 32, 15-30.

Addinsoft. (2020). XLSTAT statistical and data analysis solution. New York, USA. https://www.xlstat. com.

Agol, D., Latawiec, A. E., \& Strassburg, B. B. (2014). Evaluating impacts of development and conservation projects using sustainability indicators: Opportunities and challenges. Environmental Impact Assessment Review, 48, 1-9.

Alaimo, L. S. (2020). Complexity of social phenomena: Measurements, analysis, representations and synthesis. Unpublished doctoral dissertation, University of Rome "La Sapienza", Rome, Italy.

Alaimo, L. S., \& Maggino, F. (2020). Sustainable development goals indicators at territorial level: conceptual and methodological issues-The Italian perspective. Social Indicators Research, 147(3), 383-419. https://doi.org/10.1007/s11205-019-02162-4

Alaimo, L. S., Ciacci, A., \& Ivaldi, E. (2021). Measuring sustainable development by non-aggregative approach. Social Indicators Research, 157(1), 101-122.

Alaimo, L. S., Arcagni, A., Fattore, M., et al. (2020). Measuring equitable and sustainable well-being in italian regions: the non-aggregative approach. Social Indicators Research. https://doi.org/10.1007/ s11205-020-02388-7

Arbolino, R., De Simone, L., Carlucci, F., Yigitcanlar, T., \& Ioppolo, G. (2018). Towards a sustainable industrial ecology: Implementation of a novel approach in the performance evaluation of Italian regions. Journal of Cleaner Production, 178, 220-236.

Asheim, B. T., Lawton Smith, H., \& Oughton, C. (2011). Regional innovation systems: Theory, empirics and policy. Regional Studies, 45(7), 875-891. https://doi.org/10.1080/00343404.2011.596701

ASviS-Alleanza Italiana per lo Sviluppo Sostenibile (2021). 5 anni di ASviS —Storia di un'Alleanza per l'Italia del 2030, Editron, Roma. https://asvis.it/public/asvis2/files/Pubblicazioni/5_ANNI_ASviS_ 1_.pdf 
Avilés-Sacoto, S. V., Cook, W. D., Güemes-Castorena, D., \& Zhu, J. (2020). Modelling efficiency in regional innovation systems: A two-stage data envelopment analysis problem with shared outputs within groups of decision-making units. European Journal of Operational Research, 287(2), 572-582.

Becheikh, N., Landry, R., \& Amara, N. (2006). Lessons from innovation empirical studies in the manufacturing sector: A systematic review of the literature from 1993-2003. Technovation, 26, 644-664. https://doi.org/10.1016/j.technovation.2005.06.016

Bhatti, Y. A., \& Ventresca, M. (2012). The emerging market for frugal innovation: fad, fashion, or fit?. Fashion, or Fit.

Bianchi, A., \& Biffignandi, S. (2020). Workplace social environment indicator: A comparative analysis of European Regions. Social Indicators Research. https://doi.org/10.1007/s11205-020-02344-5

Boons, F., \& Lüdeke-Freund, F. (2013). Business models for sustainable innovation: State-of-the-art and steps towards a research agenda. Journal of Cleaner Production, 45, 9-19.

Bottazzi, L., \& Peri, G. (2003). Innovation and spillovers in regions: Evidence from European patent data. European Economic Review, 47(4), 687-710.

Bureau van Dijk, (2010). AMADEUS : a Database of Comparable Financial Information for Public and Private Companies Across Europe. Bureau van Dijk Electronic Publishing

Carayannis, E. G., Goletsis, Y., \& Grigoroudis, E. (2018). Composite innovation metrics: MCDA and the quadruple innovation helix framework. Technological Forecasting and Social Change, 131, 4-17. https://doi.org/10.1016/j.techfore.2017.03.008

Caroleo, F. E., Rocca, A., Mazzocchi, P., \& Quintano, C. (2020). Being NEET in Europe before and after the economic crisis: An analysis of the micro and macro determinants. Social Indicators Research, 149(3), 991-1024. https://doi.org/10.1007/s11205-020-02270-6

Casadio Tarabusi, E., \& Guarini, G. (2013). An unbalance adjustment method for development indicators. Social Indicator Research, 112, 19-45. https://doi.org/10.1007/s11205-012-0070-4

Cataldo, R., Crocetta, C., Grassia, M. G., Lauro, N. C., Marino, M., \& Voytsekhovska, V. (2020). Methodological PLS-PM framework for SDGs system. Social Indicators Research, 150, 1-23. https:// doi.org/10.1007/s11205-020-02271-5

Cataldo, R., Grassia, M. G., Lauro, N. C., \& Marino, M. (2017). Developments in higher-order PLSPM for the building of a system of composite indicators. Quality and Quantity, 51(2), 657-674.

Crocetta, C., Antonucci, L., Cataldo, R., Galasso, R., Grassia, M. G., Lauro, C. N., \& Marino, M. (2021). Higher-order PLS-PM approach for different types of constructs. Social Indicators Research, 154(2), 725-754.

Chin, W. W. (1998). The partial least squares approach to structural equation modeling. Modern Methods for Business Research, 295(2), 295-336.

D’Urso, P., Alaimo, L. S., De Giovanni, L., et al. (2020). Well-being in the Italian Regions over time. Social Indicators Research. https://doi.org/10.1007/s11205-020-02384-x

D’Urso, P., \& Vitale, V. (2021). Modeling Local BES Indicators by Copula-Based Bayesian Networks. Social Indicators Research, 153(3), 823-847.

Dahlander, L., \& Gann, D. M. (2010). How open is innovation? Research Policy, 39(6), 699-709.

Dewangan, V., \& Godse, M. (2014). Towards a holistic enterprise innovation performance measurement system. Technovation, 34(9). Doi: https://doi.org/10.1016/j.technovation.2014.04.002.

Dodgson, M., \& Hinze, S. (2000). Indicators Used to Measure the Innovation Process: Defects and Possible Remedies. Research Evaluation, 9(2). Doi: https://doi.org/10.3152/147154400781777368.

Durst, S., \& Edvardsson, I. R. (2012). Knowledge Management in SMEs: A literature review. Journal of Knowledge Management, 16(6), 879-903.

Dziallas, M., \& Blind, K. (2019). Innovation indicators throughout the innovation process: An extensive literature analysis. Technovation, 80-81, 3-29.

European Commission (2021). Regional Innovation Scoreboard. Available at https://ec.europa.eu/docsr oom/documents/46032/attachments/1/translations/en/renditions/native

European Commission (2019). SME Performance Review: Italy. https:/ec.europa.eu/growth/smes/busin ess-friendly-environment/performance-review_en. Accessed on May 6, 2020.

European Commission (2020), European Innovation Scoreboard. Luxembourg. Available at https://ec. europa.eu/docsroom/documents/42981/attachments/1/translations/en/renditions/nativeEurostat (2016). Energy, Transport and Environment Indicators -2016 Edition. Statistical Books, Luxembourg. http: //ec.europa.eu/eurostat/documents/3217494/7731525/KS-DK-16-001-EN-N.pdf/ cc2b4de7-146c-4254-9521-dcbd6e6fafa6.

Eurostat (2017). Eurostat Regional Yearbook 2017, Statistical books, Luxembourg. http: // ec.europa.eu/eurostat/documents/3217494/8222062/KS-HA-17-001-EN-N.pdf/ eaebe7fa-0c80-45af-ab41-0f806c433763. 
Eurostat (2018). Nace rev. 2, Statistical classification of economic activities in the European Community, Methodologies and Working Papers. https://ec.europa.eu/eurostat/documents/3859598/59025 21/KS-RA-07-015-EN.PDF

Evanschitzky, H., Eisend, M., Calantone, R., \& Yuanyuan, J. (2012). Success factors of product innovation: An updated meta-analysis. Journal of Product Innovation Management, 29(1), 21-37. https:// doi.org/10.1111/j.1540-5885.2012.00964.x

Freeman, C., \& Soete, L. (2009). Developing science, technology and innovation indicators: What we can learn from the past. Research Policy, Elsevier, 38(4), 583-589.

Fritsch, M., \& Aamoucke, R. (2013). Regional public research, higher education, and innovative startups: An empirical investigation. Small Business Economics, 41(4), 865-885.

Gössling, T., \& Rutten, R. (2007). Innovation in Regions. European Planning Studies, 15, 253-270.

Griliches, Z. (1984). $R \& D$, Patents, and Productivity. University of Chicago Press.

Griliches, Z. (1990). Patent statistics as economic indicators: A survey. Journal of Economic Literature, 28(4), 1661-1707.

Hagedoorn, J., \& Cloodt, M. (2003). Measuring innovative performance: Is there an advantage in using multiple indicators? Research Policy, 32(8), 1365-1379.

Han, J., Pei, J., \& Kamber, M. (2011). Data mining: Concepts and techniques. Elsevier.

Hair, J.F., Hult, G.T.M., Ringle, C. \& Sarstedt, M. (2016). A primer on partial least squares structural equation modeling (PLS-SEM). Sage publications.

Hair, J. F., Ringle, C. M., \& Sarstedt, M. (2011). PLS-SEM: Indeed a Silver Bullet. Journal of Marketing Theory and Practice, 19(2), 139-152. https://doi.org/10.2753/MTP1069-6679190202

Hair, J.F., Risher, J.J., Sarstedt, M. \& Ringle, C.M. (2019). When to use and how to report the results of pls-sem, European Business Review.

Hall, J., \& Clark, W. (2003). Introduction to the special issue on environmental innovation. Journal of Cleaner Production, 11(4), 343-346.

Hauser, C., Siller, M., Schatzer, T., Walde, J., \& Tappeiner, G. (2018). Measuring regional innovation: A critical inspection of the ability of single indicators to shape technological change. Technological Forecasting and Social Change, 129, 43-55. https://doi.org/10.1016/j.techfore.2017.10.019

Jaffe, A. B. (1989). Real effects of academic research. American Economic Review, 79(5), 957-970.

Joint Research Centre-European Commission. (2008). Handbook on constructing composite indicators: methodology and user guide. OECD publishing.

ISTAT (2019). SDGS report. Statistical information for 2030 agenda in Italy, Rome. https://www.istat.it/ it/files/2019/08/SDGs-2019_inglese.pdf.

Khalid, A. M., Sharma, S., \& Dubey, A. K. (2020). Data gap analysis, indicator selection and index development: A case for developing economies. Social Indicators Research, 148(3), 893-960.

Kaplan, D. (2008). Structural equation modeling: Foundations and extensions. Sage Publications.

Kuc-Czarnecka, M., Lo Piano, S., \& Saltelli, A. (2020). Quantitative storytelling in the making of a composite indicator. Social Indicator Research, 149, 775-802.

Lauro, C. N., Grassia, M. G., \& Cataldo, R. (2018). Model based composite indicators: New developments in partial least squares-path modeling for the building of different types of composite indicators. Social Indicators Research, 135(2), 421-455.

Lukkarinen, A., Teich, J. E., Wallenius, H., \& Wallenius, J. (2016). Success drivers of online equity crowdfunding campaigns. Decision Support Systems, 87, 26-38. https://doi.org/10.1016/j.dss.2016. 04.006

Maggino, F. (2017). Developing indicators and managing the complexity. In Complexity in society: From indicators construction to their synthesis (pp. 87-114). Springer, Cham.

Maier, D., Maier, A., Așchilean, I., Anastasiu, L., \& Gavriș, O. (2020). The relationship between innovation and sustainability: A bibliometric review of the literature. Sustainability, 12(10), 4083. https:// doi.org/10.3390/su 12104083

Makkonen, T., \& van der Have, R. P. (2013). benchmarking regional innovative performance: Composite measures and direct innovation counts. Scientometrics, 94(1), 247-262.

Malesios C., De D., Moursellas A., Dey P.K., \& Evangelinos K. (2021), Sustainability performance analysis of small and medium sized enterprises: Criteria, methods and framework. Socio-Economic Planning Sciences, 75

Massoli, P., Mazziotta, M., Pareto, A. \& Rinaldelli, C. (2013). Metodologie di sintesi sperimentali per i domini del bes. Xxxiv conferenza italiana di scienze regionali. Palermo. https://www.aisre.it/xxxivconferenza-scientifica-annuale-2013/

Mazziotta, M., \& Pareto, A. (2018). Measuring Well-Being over Time: THe Adjusted Mazziotta-Pareto Index versus Other Non-Compensatory Indices. https://doi.org/10.1007/s11205-017-1577-5 
Mazziotta, M., \& Pareto, A. (2017). Synthesis of indicators: The composite indicators approach. In F. Maggino (Ed.), Complexity in society: From indicators construction to their synthesis (pp. 59-191). Springer.

Mazziotta, C., Mazziotta, M., Pareto, A., \& Vidoli, F. (2010). La sintesi di indicatori territoriali di dotazione infrastrutturale: Metodi di costruzione e procedure di ponderazione a confronto. Review of Economics and Statistics for Regional Studies, 1, 7-33.

Mehmetoglu, M., \& Venturini, S. (2021). Structural equation modelling with partial least squares using stata and R. 345

MISE - Ministry of Economic Development (2020), Agevolazioni a favore delle PMI innovative. https://www.mise.gov.it/images/stories/documenti/Sito_Agevolazioni_PMI_innovative_ITA_Ottob re_2020.pdf

Moura, T.G.Z., Garcia-Alonso, L., \& Salas-Olmedo, M.H. (2017). Delimiting the scope of the hinterland of ports: proposal and case study. Journal of Transport Geography . 65(C), 35-43.

Nardo, M., Saisana, M., Saltelli, A., Tarantola, S., Hoffman, A., \& Giovannini, E. (2005). Handbook on Constructing Composite Indicators: Methodology and User Guide. OECD Statistics Working Papers. OECD Publishing.

OECD. (2011). Regions and innovation policy. OECD Reviews of Regional Innovation, OECD Publishing, Paris, . https://doi.org/10.1787/9789264097803-en

OECD, Eurostat (2018a). The Evaluation of the Italian Start-Up Act, Oecd publishing, https://www. oecd-ilibrary.org/docserver/02ab0eb7-en.pdf?expires $=1610467199 \& \mathrm{id}=\mathrm{id} \&$ accname $=$ guest $\&$ checksum $=$ CAE73A5EE6B8962F2D76D31617D2D7E7

OECD, Eurostat (2018b). Oslo Manual 2018: The measurement of scientific and technological activities: Guidelines for collecting, reporting and using data on innovation. (4th ed.). OECD Publishing, Paris.

Oksanen, K., \& Hautamäki A. (2015). Sustainable Innovation: A Competitive Advantage for Innovation Ecosystems. Technology Innovation Management Review, 5(10), 24-30. Doi: https://doi.org/ 10.22215/timreview/934.

Peiró-Palomino, J., \& Picazo-Tadeo, A. J. (2018). OECD: One or many? Ranking countries with a composite well-being indicator. Social Indicators Research, 139(3), 847-869. https://doi.org/10.1007/ s11205-017-1747-5

Pollesch, N. L., \& Dale, V. H. (2016). Normalization in sustainability assessment: Methods and implications. Ecological Economics, 130, 195-208.

Porter, M. E., \& Kramer, M. (2011). Creating Shared Value: How to reinvent capitalism-and unleash the wave of innovation and growth. Harvard Business Review, 89(1/2), 62-77.

Quintano, C., \& Mazzocchi, P. (2020). Examining a multi-dimensional undeclared work via the REBUSPLS. Journal of Economic Studies, 47(2), 405-430. https://doi.org/10.1108/JES-08-2018-0288

Quintano, C., Mazzocchi, P., \& Rocca, A. (2020). Examining eco-efficiency in the port sector via nonradial data envelopment analysis and the response based procedure for detecting unit segments. Journal of Cleaner Production, 259, 120979. https://doi.org/10.1016/j.jclepro.2020.120979

Radjou, N., Prabhu, J., \& Ahuja, S. (2012). Jugaad Innovation: Think Frugal, Be Flexible. Jossey-Bass.

Ratten, V. (2018). Sustainable farming entrepreneurship in the Sunraysia region. International Journal of Sociology and Social Policy, 38(1/2), 103-115.

Ratten, V., \& Dana, L. P. (2017). Sustainable entrepreneurship, family farms and the dairy industry. International Journal of Social Ecology and Sustainable Development, 8(3), 114-129.

Ratten, V., Jones, P., Braga, V., \& Marques, C. S. (2019). Subsistence entrepreneurship: The role of collaborative innovation, sustainability and social goals. Springer.

Rennings, K. (2000). Redefining innovation-Eco-innovation research and the contribution from ecological economics. Ecological Economics, 32(2), 319-332. https://doi.org/10.1016/S0921-8009(99)00112-3

Ringle, C. M., \& Sarstedt, M. (2016). Gain more insight from your PLS-SEM results The importanceperformance map analysis. Industrial Management and Data Systems, 116(9), 1865-1886. https:// doi.org/10.1108/IMDS-10-2015-0449

Rothwell, R. (1992). Successful industrial innovation: Critical factors for the 1990s R\&D. Management, 22(3), 221-238.

Schiederig, T., Tietze, F., \& Herstatt, C. (2012). Green innovation in technology and innovation management: An exploratory literature review. $R \& D$ Management, 42, 19-192.

Sessa M. (2016), Measuring and Monitoring the Achievements of the Millennium Development Goals Through Dynamic Composite Indices. Social Indicators Research, 127 (2)

Shmueli, G., Ray, S., Velasquez Estrada, J. M., \& Chatla, S. B. (2016). The elephant in the room: Predictive performance of PLS models. Journal of Business Research, 69(10), 4552-4564. https://doi.org/ 10.1016/J.JBUSRES.2016.03.049 
Shmueli, G., Sarstedt, M., Hair, J. F., Cheah, J. H., Ting, H., Vaithilingam, S., \& Ringle, C. M. (2019). Predictive model assessment in PLS-SEM: Guidelines for using PLSpredict. European Journal of Marketing, 53(11), 2322-2347. https://doi.org/10.1108/EJM-02-2019-0189

Smith, K. (2005). Measuring Innovation. In J. Fagerberg, D. Mowery, \& R. Nelson (Eds.), The Oxford handbook of innovation (pp. 148-177). Oxford University Press.

Sodano, V. (2019). Innovation Trajectories and Sustainability in the Food System. Sustainability, 11, 1271. https://doi.org/10.3390/su11051271

Tenenhaus, M., Esposito Vinzi, V., Chatelin, Y. M., \& Lauro, C. N. (2005). PLS path modeling. Computational Statistics and Data Analysis, 48(1), 159-205.

Tomaselli, V., Fordellone, M., \& Vichi, M. (2020). building well-being composite indicator for micro-territorial areas through PLS-SEM and K-means approach. Social Indicators Research, 153, 407-429. https://doi.org/10.1007/s11205-020-02454-0

Trinchera, L., Russolillo, G., \& Lauro, C. N. (2008). Using categorical variables in PLS path modeling to build system of composite indicators. Statistica Applicata, 20(3-4), 309-330.

United Nations (2015a). Transforming our world: The 2030 agenda for sustainable development. General Assembly 70 session.

United Nations (2015b). United Nations Conference on Sustainable Development, Rio+20.

Van Holt, T., Statler, M., Atz, U., Whelan, T., Loggerenberg, M., \& Cebulla, J. (2020). The cultural consensus of sustainability-driven innovation: Strategies for success. Business Strategy and the Environment, 29(8), 3399-3409. https://doi.org/10.1002/bse.2584

WCED, Special Working Session (1987). World commission on environment and development. Our common future (vol. 17, pp. 1-91). Oxford University Press, London.

Wetzels, M., Odekerken-Schröder, G., \& Van Oppen, C. (2009). Using PLS path modeling for assessing hierarchial construct models: Guidelines and empirical illustration. MIS Quarterly, 33(1), 177-195.

Publisher's Note Springer Nature remains neutral with regard to jurisdictional claims in published maps and institutional affiliations. 